\title{
Can a community health worker and a trained traditional birth attendant work as a team to deliver child health interventions in rural Zambia?
}

\author{
Kojo Yeboah-Antwi ${ }^{1,2 *}$, Davidson H Hamer ${ }^{1,2,3}$, Katherine Semrau ${ }^{1,2}$, Karen Z Waltensperger ${ }^{4}$, Gail Snetro-Plewman ${ }^{4}$, \\ Chilobe Kambikambi ${ }^{5}$, Amon Sakala ${ }^{5}$, Stephen Filumba ${ }^{5}$, Bias Sichamba ${ }^{5}$ and David R Marsh ${ }^{6}$
}

\begin{abstract}
Background: Teaming is an accepted approach in health care settings but rarely practiced at the community level in developing countries. Save the Children trained and deployed teams of volunteer community health workers (CHWs) and trained traditional birth attendants (TBAs) to provide essential newborn and curative care for children aged 0-59 months in rural Zambia. This paper assessed whether CHWs and trained TBAs can work as teams to deliver interventions and ensure a continuum of care for all children under-five, including newborns.

Methods: We trained CHW-TBA teams in teaming concepts and assessed their level of teaming prospectively every six months for two years. The overall score was a function of both teamwork and taskwork. We also assessed personal, community and service factors likely to influence the level of teaming.

Results: We created forty-seven teams of predominantly younger, male CHWs and older, female trained TBAs. After two years of deployment, twenty-one teams scored "high", twelve scored "low," and fourteen were inactive. Teamwork was high for mutual trust, team cohesion, comprehension of team goals and objectives, and communication, but not for decision making/planning. Taskwork was high for joint behavior change communication and outreach services with local health workers, but not for intra-team referral. Teams with members residing within one hour's walking distance were more likely to score high.
\end{abstract}

Conclusion: It is feasible for a CHW and a trained TBA to work as a team. This may be an approach to provide a continuum of care for children under-five including newborns.

Keywords: Teams, Teaming, Teamwork, Taskwork, Continuum of care, Community health workers, Traditional birth attendants, Newborn health, Child health care, Zambia

\section{Background}

Zambia has a strained health care system with limited health facilities and human resources, and thus has been using community-based health workers, mostly volunteers, to provide basic health services, especially in rural areas, to confront its high under-5 mortality [1,2]. Two common volunteer cadres are community health workers (CHWs) and trained traditional birth attendants (TBAs). CHWs as per government policy, have been trained to

\footnotetext{
* Correspondence: kyantwi@bu.edu

'Center for Global Health and Development, Boston University, 801

Massachusetts Ave, 3rd Floor, Boston, MA 02118, USA

${ }^{2}$ Department of Global Health, Boston University School of Public Health,

Boston, MA, USA

Full list of author information is available at the end of the article
}

provide a wide range of services, including preventive and promotive interventions, health education, community mobilization and sensitization, and treatment of common childhood illnesses (fever, diarrhea, and pneumonia) [3]. Trained TBAs have also been trained to provide maternal and newborn interventions, including antenatal and postnatal care, and recognition of and referral for danger signs of pregnant women and newborns. As per government policy, TBAs are no longer trained in clean delivery but are encouraged to accompany women to health facilities to deliver. These community-based providers are supported by Neighborhood Health Committees (NHCs), which link them with both the community and the formal health system. The NHCs are community-based health 
management structures of community members with the responsibility of analyzing health situations and problems and exploring opportunities for solving them. Their roles include supporting community-based agents during implementation of health programs, initiating and supporting developmental activities to improve community and household health, and mobilizing community and local resources for health improvement. They represent communities on health center committees [3]. In this setting the NHCs play key roles in health delivery system and are seen as important partners by both the DHMT and the health center staff.

Trained TBAs and CHWs may reside in the same community, but work independently of each other, leading to inefficiency and missed opportunities for continuity of care. There is a growing recognition that health interventions for newborns should be integrated into child health programs [4] to promote a continuum of care, an approach expected to promote care for mothers and children from pregnancy to delivery, and into the immediate postnatal period and childhood [5].

Teaming (i.e., establishing teams of two or more individuals who work together) is an accepted approach in various settings, including health care, in both developed and developing countries; and it has increasingly become a critical approach in health care delivery [6-8], but it is not practiced with community-based health workers. Characteristically, team members generally have specialized knowledge and specific roles, make decisions, perform interdependent tasks, are adaptable, and share a common goal [9-11]. Benefits of a team include distributing workload, reinforcing individual capabilities, creating the feeling of participation and involvement, making better decisions, and generating a diversity of ideas for a common purpose [12]. Teamwork consists of behaviors related to team member interactions to achieve team goals, such as goal comprehension, communication, conflict management, decision-making/planning, leadership, mutual performance monitoring, mutual trust, team cohesion and team motivation [11,13-16]. Teamwork has increasingly been recognized by several organizations as important for improving healthcare [17-19]. Taskwork, on the other hand, consists of behaviors performed by individual team members to execute team functions [20,21].

Save the Children in collaboration with the Boston University Center for Global Health and Development (BU/CGHD) and the Ministry of Community Development, Mother and Child Health (MCDMCH), the Ministry of Health $(\mathrm{MOH})$, and the Lufwanyama District Health Management Team (DHMT) is implementing the Lufwanyama Integrated Neonatal and Child Health Project in Zambia (LINCHPIN). LINCHPIN is an integrated, community-based newborn care and community case management package delivered through an enhanced district-wide community health program linked to health facilities and NHCs in a manner consistent with the Zambia $\mathrm{MOH}$ plans and policies and $\mathrm{MCDMCH}$ strategies and approaches [2,3]. The project teams CHWs and trained TBAs, supported by NHCs, to provide a continuum of evidence-based essential newborn and curative care for children 0-59 months of age in Lufwanyama District. The rationale for integration and teaming is to achieve efficiency, since the effect of the team will likely exceed the effects of the individuals working alone and also improve social cohesion and sense of community. This paper assessed whether CHWs and trained TBAs can work together in teams to provide integrated care to newborn and sick children in rural Zambia.

\section{Methods}

\section{Study location}

The study was conducted in Lufwanyama District in the Copperbelt Province of Zambia. Lufwanyama is a large, rural, undeveloped district with an estimated 2011 population of 87,592 [22], with the majority belonging to the Lamba ethnic group. Despite its location in the comparatively urban, industrialized Copperbelt, the district lacks physical infrastructure, and many roads are impassible during the rainy season. It has 12 health centers, five health posts and a newly opened district hospital. The DHMT operated for many years outside the district, but is currently housed at the new district hospital. Many basic health services, including treatment of minor illnesses, health education, antenatal care, family planning services, follow-up of patients with chronic illnesses and referrals, are provided through several categories of minimally trained community workers trained TBAs, CHWs, male motivators, safe motherhood agents, family planning agents, disease surveillance agents, malaria agents, tuberculosis agents, HIV/ AIDS agents, and untrained TBAs. The Lufwanyama DHMT, with support from non-governmental partners operating in the district, have trained and deployed CHWs and trained TBAs for over 30 years. CHWs and trained TBAs spend some days in a week working with health center staff at facilities. The health centers provide them with drugs and supplies and health workers supervise their work.

\section{Study design}

This prospective study assessed the level of teamwork and taskwork among community-based CHW-TBA teams supported by NHC members. We used an assessment tool developed through formative research with community leaders, health workers, CHWs and trained TBAs [23]. We carried out the assessment every six months from June 2011 to March 2013. 


\section{Team creation and training}

A CHW and trained TBA working in the same community formed the CHW-TBA team. We did not create teams for communities which had only a $\mathrm{CHW}$ or trained TBA. The CHW-TBA team plus two NHC support members were trained in teaming concepts prior to deployment. The training addressed both specific tasks (Table 1) that the teams would undertake as well as the skills and competencies to maintain a functioning team. The teamwork skills and competencies included i) good communication; ii) respectful dialogue and action; iii) each helping the other, mutual support, and working hand in hand; iv) assess, make decisions and manage conflicts; v) trust and confidentiality of care-seekers/community members; vi) together monitor team task and team maintenance abilities; vii) evaluate successes and failures; viii) asking for feedback; and ix) motivate and encourage each other. The specific tasks and skills required for successful community teams were identified during earlier formative research [23].The training emphasized the importance of performing the joint tasks and the need to document tasks performed. They practiced and demonstrated how to perform these tasks. The training utilized several methods including exercises, practice, demonstrations, role play,

\section{Table 1 Taskwork description}

\begin{tabular}{ll}
\hline Task & Description \\
\hline Meeting with NHCs & This task requires the team to meet \\
& with NHC to discuss CHW/TBA team \\
& work and performance including \\
& challenges and the support needed.
\end{tabular}

Conducting behavior change Sessions in the community to educate communication (BCC) community members in relevant health topics including exclusive breastfeeding, disease prevention, danger signs in pregnancy and childhood illnesses, importance of antenatal and postnatal care, hygiene and sanitation.

Problem solving for newborn Home visits including follow-up visits and child care to help and support caregivers in their care of children such as individual counselling, addressing challenges and seeking care

Outreach services

Publicizing dates of outreach, mobilizing caregivers to attend and performing specific activities during sessions.

Support Referral

Convincing caregivers and households on the need to accept a referral and help with mobilizing transport

Intra-team referral

CHW referring pregnant or postnatal women seen at clinic or during a home visit to the trained TBA for follow-up. Trained TBA referring sick child seen on home visit or at postnatal care to CHW for treatment and advice.

Postnatal care visit at 6-8 weeks experience sharing brainstorming and real-life scenarios for the teams to acquire the necessary knowledge and skills of teamwork competences for maintaining functioning teams. The training also clarified roles of the NHCs as identified by the $\mathrm{MOH}$ guidelines [3].

\section{Baseline data collection}

Prior to training, we collected baseline information from team members, including age, gender, education, ethnic group, marital status, religion, membership of a social group (e.g. faith-based fellowships, parent-teacher associations, corporative societies, etc.), length of service, other occupation, and walking time from each other.

\section{Team assessment}

An independent, non-LINCHPIN data collector visited the core team members (CHW and trained TBA) and administered a three-part team measurement tool. The first assessment started two months after the teaming training. Part A was administered to both members together and assessed taskwork, i.e., whether the team had jointly performed any of seven agreed specific tasks in the previous three months: 1) meeting with NHCs to discuss work and performance, 2) conducting behavior change communications sessions targeting women on newborn and child care, 3) problemsolving for newborn or child care, 4) participating in outreach services, 5) supporting referral of a pregnant woman or sick child, 6) conducting intra-team referral, and 7) conducting postnatal care visits to a mother with a newborn aged 6-8 weeks. The team scored "0" if a function was not performed, " 1 " if performed but without documented evidence, and " 2 " if there was documented evidence of performance. Part B was administered separately to the CHW and trained TBA. It assessed 27 characteristics from eight teamwork processes identified during the formative research [23]: 1) mutual performance monitoring, 2) mutual trust, 3) decision making/planning, 4) team cohesion, 5) team motivation, 6) goals and objectives, 7) communication, and 8) conflict resolution/management. Data were collected from each member about whether, in his/her opinion, the characteristic was present in the team over the previous six months. They scored "1" if a member reported that the characteristic was not or hardly present in the team; " 2 " if it was present sometimes; and " 3 " if present all the time. The score for the team was the average score of the two members. Part $\mathrm{C}$ - also administered separately to each individual team member - collected information on perceived factors that may influence teamwork such as supervision, refresher training, availability of supplies, incentives, and ownership of bicycle or cell phone.

\section{Team score and classification and analysis}

The score for the taskwork of each team at each assessment was the sum of the scores of the seven functions. weeks in order for the trained TBA to "hand over" care of child to the CHW. 
The overall taskwork score for the teams was the mean score of the four assessments. For teamwork, the score for the team at each assessment was the average score of the two members from the twenty seven indicators (expressed as a percent). The overall teamwork score was also the mean score of the four assessments.

A team was categorized "inactive" if unavailable for an assessment and the local NHC confirmed its inactivity and break-up. We categorized the remaining teams "high" if the mean score on the taskwork scale was $\geq 7$ of a possible 14 , and the mean score on the teamwork scale was $\geq 90 \%$; and "low" if the taskwork score was $<7$ or teamwork score was $<90 \%$. We decided on the cut-offs prior to data collection, but we modified the categorization based on the distribution of the teamwork scores. In order to evaluate factors that may influence the level of teaming, frequency and proportions were compared with chi-square test; odds ratios (OR) and 95\% confidence intervals (CI) were calculated for each characteristic. All data analysis was conducted in EpiInfo software package [24].

\section{Ethical issues}

Ethical approval was obtained from the Boston University Institutional Review Board (BU-IRB) and a local Zambian ethical review committee (ERES CONVERGE). Informed consent was obtained from all study participants with a consent form developed in accordance with guidelines of the BU-IRB and the local ethical review committee and translated into Bemba, the language of common communication in the district. During consenting, study personnel explained the purpose and rationale of the study, informed the participants that they were not obliged to participant in the research, and assured them of the confidentiality of the information collected from them.

\section{Results}

Team characteristics

The project created and trained 47 . There were $74 \mathrm{CHWs}$ operating in the district but some CHWs did not have a trained TBA operating in their communities. The CHWs were predominantly male $(80.9 \%)$, and the trained TBAs were all female (Table 2). CHWs were younger than the trained TBAs (average age of 44 years vs 53 years). Most CHWs had more schooling than the trained TBAs. Half the trained TBAs were of the local Lamba ethnic group while only a third of the CHWs were Lamba. CHWs were more likely to be currently married than the trained TBAs. Only about a fifth of the CHWs and the trained TBAs reported that being a CHW or TBA was their main occupation.

\section{Overall team categorization}

We categorized $21(44.7 \%)$ teams as high, $12(25.5 \%)$ as low, and $14(29.8 \%)$ as inactive. Three teams became
Table 2 Baseline characteristics of team members

\begin{tabular}{|c|c|c|}
\hline Characteristics & $\mathrm{CHW}(\mathrm{n}=47)$ & TBA $(n=47)$ \\
\hline \multicolumn{3}{|l|}{ Age: (years) } \\
\hline Average (SD) & $44.4(8.8)$ & $53.0(6.6)$ \\
\hline Range & $28-69$ & $33-66$ \\
\hline \multicolumn{3}{|l|}{ Sex: } \\
\hline Male & $80.9 \%$ & 0 \\
\hline Female & $19.1 \%$ & $100 \%$ \\
\hline \multicolumn{3}{|l|}{ Educational Level } \\
\hline No education & 0 & $8.5 \%$ \\
\hline Primary & $14.9 \%$ & $68.1 \%$ \\
\hline Secondary & $85.1 \%$ & $23.4 \%$ \\
\hline \multicolumn{3}{|l|}{ Ethnic Group } \\
\hline Lamba & $36.2 \%$ & $50 \%$ \\
\hline Bemba & $14.9 \%$ & $16.5 \%$ \\
\hline Kaonde & $2.1 \%$ & $2.2 \%$ \\
\hline Other & $46.8 \%$ & $41.3 \%$ \\
\hline \multicolumn{3}{|l|}{ Marital status } \\
\hline Single/not married & 0 & $2.1 \%$ \\
\hline Married & $91.3 \%$ & $66.0 \%$ \\
\hline Separated/divorced & $2.2 \%$ & $6.4 \%$ \\
\hline Widowed & $6.5 \%$ & $25.5 \%$ \\
\hline \multicolumn{3}{|l|}{ Religion } \\
\hline Christian (Jehovah witness) & $31.9 \%$ & $19.2 \%$ \\
\hline Christian (Catholic) & $12.8 \%$ & $10.6 \%$ \\
\hline Christian (Pentecostal) & $6.4 \%$ & $10.6 \%$ \\
\hline African Christian Church & $25.5 \%$ & $44.7 \%$ \\
\hline Other & $23.4 \%$ & $14.9 \%$ \\
\hline \multicolumn{3}{|l|}{ Main Occupation } \\
\hline $\mathrm{CHW/TBA}$ & $23.9 \%$ & $19.2 \%$ \\
\hline Farmer & $76.1 \%$ & $80.8 \%$ \\
\hline \multicolumn{3}{|l|}{ Length of Service (years) } \\
\hline Average (SD) & $9(5.9)$ & $11.3(7.7)$ \\
\hline Range & $1-28$ & $3-40$ \\
\hline
\end{tabular}

inactive after the first assessment, four after the second, and the remaining seven after the third. CHW departure, usually to find a new job, was responsible for most of the inactive teams (71.4\%) (Table 3). Two CHWs were employed as casual laborers to work at rural health centers, two CHWs stopped because they became frustrated with the work and one trained TBA was forced to stop because some members of the community believed she was not representing community values.

\section{Teamwork performance}

All team members reported the presence of mutual trust within their teams during all four assessments (Table 4). 
Table 3 Reasons for inactive teams

\begin{tabular}{llll}
\hline Reason & $\begin{array}{l}\text { CHW (n= 47) } \\
\mathbf{n}(\%)\end{array}$ & $\begin{array}{l}\text { TBA ( } \mathbf{n = 4 7 )} \\
\mathbf{n}(\%)\end{array}$ & $\begin{array}{l}\text { Total }(\mathbf{n}=\mathbf{9 4}) \\
\mathbf{n}(\%)\end{array}$ \\
\hline Found new job & $5(10.6)$ & 0 & $5(5.3)$ \\
Relocated to another area & $2(4.3)$ & $2(4.3)$ & $4(4.3)$ \\
Illness/old age & $1(2.1)$ & $1(2.1)$ & $2(2.1)$ \\
Frustration & $2(4.3)$ & 0 & $2(2.1)$ \\
Forced to stop & 0 & $1(2.1)$ & $1(1.1)$ \\
Total & $10(21.3)$ & $4(8.5)$ & $14(14.9)$ \\
\hline
\end{tabular}

Many team members reported comprehension of team goals and objectives and team cohesion as present most of the time. On the other hand, decision making/planning and mutual performance monitoring were reported lacking in most cases. The teams reported only six conflicts in the four assessments, all of which were satisfactorily resolved or managed. Team motivation and communication were reported to have improved over time while mutual performance monitoring and decision making/planning after initial improvement, declined during the last assessment (Figure 1).

\section{Taskwork performance}

Table 5 shows reported and documented joint activities. The most common documented joint activity was making a home visit to a mother with a young infant aged about 6-8 weeks where the trained TBA "handed over" the child to the CHW (55.3\%), followed by meeting with NHCs to discuss work and performance (36.5\%). Less commonly reported joint activities were intra-team referral (e.g., the $\mathrm{CHW}$ referring a pregnant woman to the trained TBA or the trained TBA referring a mother with a sick child to the $\mathrm{CHW}$ ) and joint problem solving (15.6 and $21.6 \%$, respectively). The most common joint activity (documented plus undocumented) was participation in outreach services, including immunization conducted by the supervising rural

\begin{tabular}{ll}
$\begin{array}{l}\text { Table } 4 \text { Teamwork Performance - proportion of teams } \\
\text { that exhibited teamwork processes during the four } \\
\text { assessments }\end{array}$ \\
\hline Teamwork dimension & Average performance \\
\hline Mutual trust & $100 \%$ \\
Goals and objectives & $98.1 \%$ \\
Team cohesion & $95.7 \%$ \\
Communication & $76.3 \%$ \\
Team motivation & $70.8 \%$ \\
Mutual performance monitoring & $41.3 \%$ \\
Decision making/planning & $38.1 \%$ \\
\hline
\end{tabular}

health center staff, and BCC sessions targeting women to educate them about newborn and child care (Figure 2). The least common activities by these criteria were intrateam referral and supporting referral to health facilities.

\section{Factors influencing teaming}

Teams with members residing within one hour's walking distance were more likely to score high $(\mathrm{OR}=5.80$; 95\% CI: 1.52-22.1; p =0.007). Teams whose members were jointly supervised were also more likely to score high $(\mathrm{OR}=3.2 ; 95 \% \mathrm{CI}: 0.83-12.74 ; \mathrm{p}=0.05)$, barely achieving statistical significance (Table 6). Teams whose members were of the same sex and with at least one member receiving some form of incentives (e.g. payment in-kind or cash from the community for services rendered) were likely to score high, but these differences were not significant.

\section{Discussion}

This study shows the feasibility of creating and deploying teams of volunteer community-based providers of relatively younger, better schooled, predominantly male CHWs and older, less schooled, female trained TBAs in a rural setting. Most of the important teamwork dimensions - i.e., mutual support, team cohesion, comprehension of team goals and objectives and communication $[6,11,25]$ - were highly present in the teams. Additionally, most teams performed many of the joint tasks. About two-thirds of the active teams were categorized as high performing.

Having a common purpose that all team members are able to articulate is fundamental to team effectiveness. Teams need to involve all members in purpose development, and everyone should be able to articulate and commit to the team's purpose. If team members have different understandings of what their common purpose is, friction, confusion, and wasted resources and effort are inevitable [26]. In our study, team scores on the comprehension of goal and objectives were high; therefore, these CHW-TBA teams had the potential to be effective in delivering integrated newborn and child care services in a rural setting. Team scores on communication were also high and improved over time, a welcome achievement since team communication failure has been associated with breakdown of teamwork, reduced outcomes, tension, stress and inefficiency [27-32].

The low score for mutual performance monitoring is of great concern. A proposed model of five key dimensions for effective teams includes mutual performance monitoring [33]. Mutual performance monitoring requires sufficient understanding of the environment to monitor other team members to identify lapses. To achieve these five dimensions, team members must respect and trust each other to give and receive performance feedback and must 


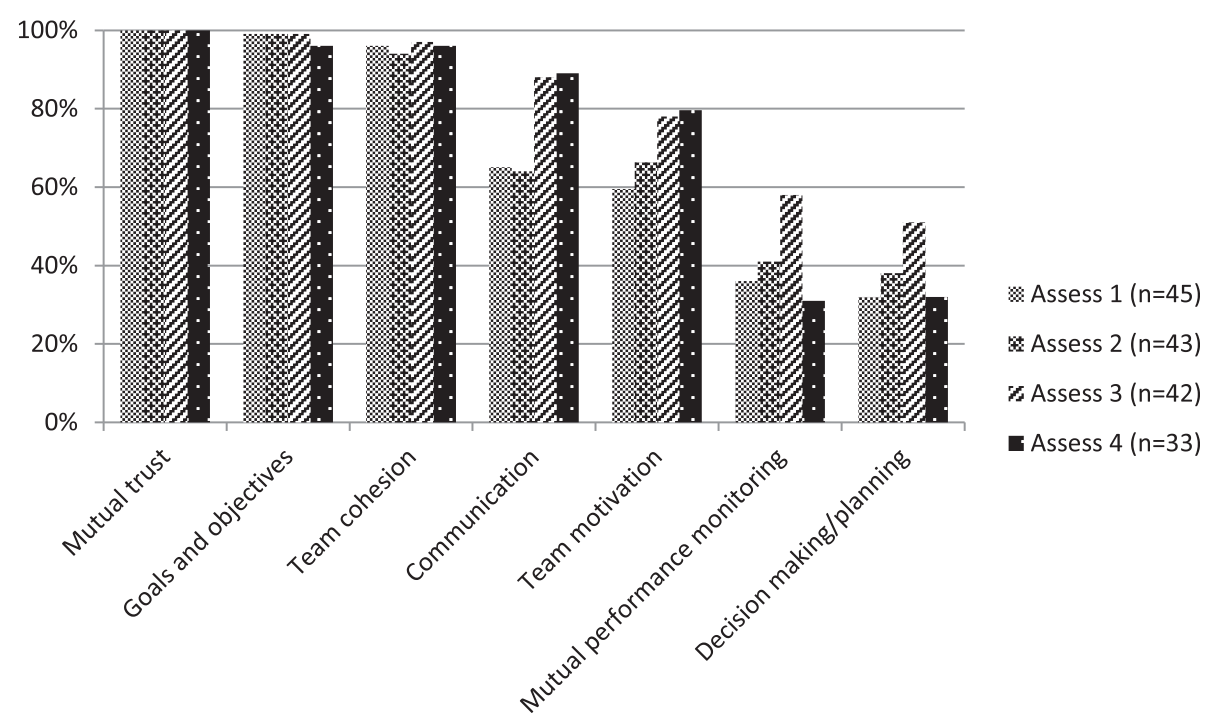

Figure 1 Teamwork performance - proportion of teams that exhibited teamwork processes during assessments.

have good communication skills to convey information accurately [34]. Despite scoring low in mutual performance monitoring, these teams had excellent scores on mutual trust and high scores on communication, so these teams have the potential to improve monitoring.

Postnatal care coverage is low in Zambia, and newborns in rural areas are less likely to have postnatal care especially within the critical first week of life than newborns in urban areas [2]. It was reassuring that one of the most commonly performed tasks was the trained TBA and CHW jointly making home visits for handover at 6-8 weeks. CHWs normally see infants from two months of age and trained TBAs are supposed to carry out home visits soon after a baby's delivery, encourage facility-based postnatal care, assess for danger signs in mother and baby, and make and follow up referrals when necessary. The joint home visits for handing over

Table 5 Taskwork - proportion of teams that performed the agreed task during the four assessments

\begin{tabular}{lll}
\hline Taskwork & $\begin{array}{l}\text { Average } \\
\text { performance } \\
\text { (documented) }\end{array}$ & $\begin{array}{l}\text { Average } \\
\text { performance } \\
\text { (undocumented) }\end{array}$ \\
\hline Attended NHC meeting & $36.5 \%$ & $50.3 \%$ \\
Conducted BCC & $31.2 \%$ & $60.3 \%$ \\
Problem solving & $21.6 \%$ & $34.5 \%$ \\
Outreach services & $21.8 \%$ & $69.8 \%$ \\
Referral to health facility & $28.1 \%$ & $24.9 \%$ \\
Intra-team referral & $15.5 \%$ & $28.3 \%$ \\
Post natal care & $55.3 \%$ & $35.3 \%$ \\
\hline
\end{tabular}

care of the young infant has the potential to underscore the importance of and improve the use of facility-based postnatal services and enhance the continuum of care. It is possible that the high performance of this task was because it was related to the responsibilities of both team members (to make home visits) and therefore it was easier to undertake joint activities that are already perceived to be part of their routine activity.

CHW-TBA teams appear to be a viable strategy to implement an integrated community-based newborn and child care interventions; however, 30\% team attrition over two years presents a challenge. This is not surprising considering that many teams received few or no incentives from their communities. Annual attrition rates as high as $77 \%$ have been reported among volunteer community-based providers [35]. Attrition is largely due to low remuneration, "movement upwards to higher positions in the health system," and finding better positions in other fields [36], similar to what we found. The importance of adequate retention and incentive structures for CHW programs is recognized as a key component of the WHO task-shifting proposal to tackle health worker shortages to contribute to the achievement of several Millennium Development Goals in low-income countries [37]. If teaming is to be implemented, approaches to motivate and retain $\mathrm{CHW}$ need to be adopted [38-41]. The development and implementation of the Zambian government's new National Community Health Worker Strategy, which established a new cadre of community health assistants who will be paid a monthly allowance by the government, may be a step in the right direction [2]. 


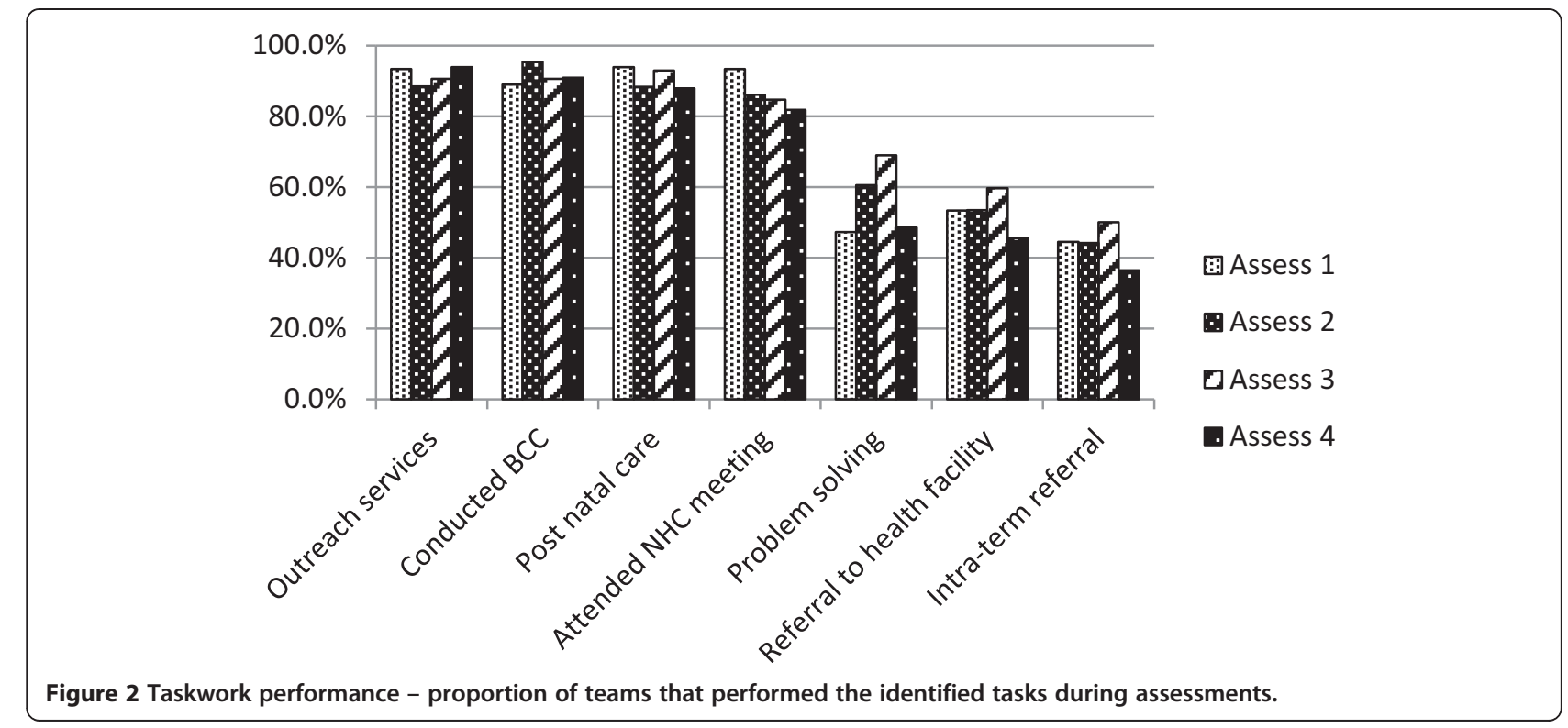

Member proximity was the main identified factor positively influencing the level of teaming. It is not surprising since this situation is likely to improve the communication and interaction between team members and thereby improve collaborative efforts.

\section{Limitations}

The study has limitations. The assessment consisted mainly of participants' subjective reports of satisfaction, attitudes, and opinions, and they may have over-rated themselves. The small sample size may have precluded

\section{Table 6 Determinants of level of teaming}

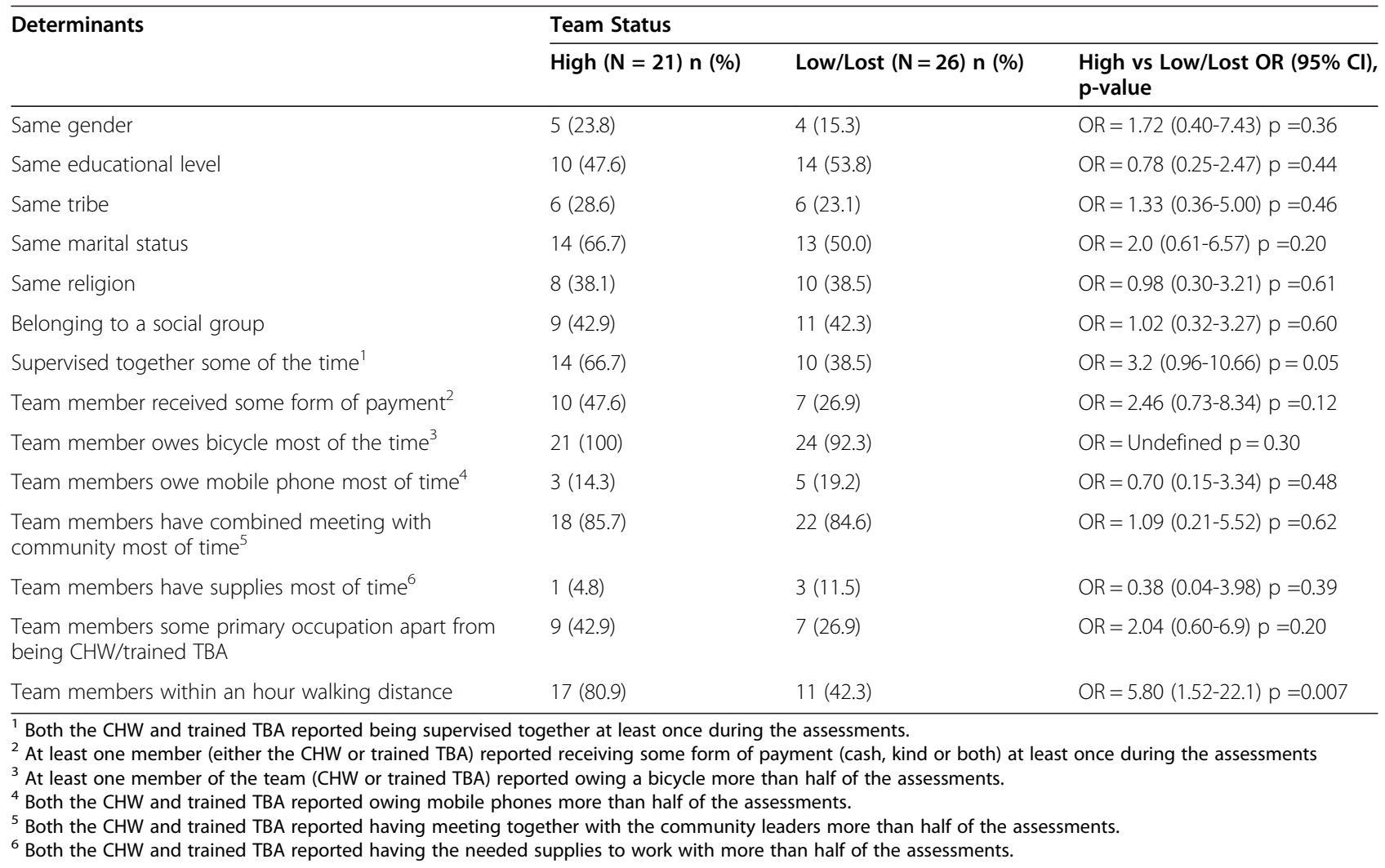


identifying other factors influencing teaming. Another limitation was that the assessment tool was not validated.

\section{Conclusions}

To our knowledge, this is the first attempt to assess the feasibility of community-based teams in a health care setting in a developing country. We measured teamwork using culturally accepted relevant teamwork dimensions and agreed upon tasks the teams were expected to perform. The teams' performances on both the teamwork and taskwork scales were encouraging. Creating, supporting, measuring and adapting teams have the potential to strengthen community capacity to improve health delivery. Communities provide the social, cultural and organizational support and allocate and manage resources to address challenges that affect their members. Teaming is likely a promising potentially sustainable approach to deliver continuous newborn and child health interventions in rural communities and may accomplish development in other sectors. The DHMT, health center staff, community leaders and members, CHWs and trained TBAs were actively involved in the development of the tool. LINCHPIN has started discussion with the DHMT about incorporating the teaming approach in the health delivery system.

\section{Abbreviations \\ BU-IRB: Boston University Institutional Review Board; CGHD: Center for Global Health and Development; CHW: Community health worker; Cl: Confidence interval; DHMT: District Health Management Team; LINCHPIN: Lufwanyama Integrated Neonatal and Child Health Project; MCDMCH: Ministry of Community Development, Mother and Child Health; MOH: Ministry of Health; NHC: Neighborhood Health Committee; OR: Odds ratio; TBA: Traditional birth attendant.}

\section{Competing interests}

The authors declare that they have no competing interests.

\section{Authors' contributions}

KYA, DM, DHH and KZW contributed to the conception and design of the study. KYA, DHH, GSP, CK, AS, SF, and BS all participated in study implementation and data collection. KYA, KS and DHH performed data analyses and DM, GSP and KZW assisted with interpretation of the data. KYA, $\mathrm{DHH}$ and DM drafted the manuscript. All authors contributed to revisions of the manuscript and read and approved the final manuscript.

\section{Acknowledgements}

We thank the NHC members, the CHWs and trained TBAs who were involved in the study. We would also like to acknowledge support from the LINCHPIN team and Save the Children country office in Kalulushi, and the Lufwanyama District Health Management Team. The study was funded under the USAID Child Survival and Health Grants Program Cooperative Agreement (GHS-A-00-09-00013-000), with additional support from the ELMA Foundation, the Crown Family Philanthropies and other private donors. The funders had no role in study design, data collection and analysis, decision to publish, or preparation of the manuscript.

\section{Author details}

${ }^{1}$ Center for Global Health and Development, Boston University, 801 Massachusetts Ave, 3rd Floor, Boston, MA 02118, USA. ${ }^{2}$ Department of Global Health, Boston University School of Public Health, Boston, MA, USA. ${ }^{3}$ Zambia Center for Applied Health Research and Development, Lusaka, Zambia. ${ }^{4}$ Save the Children, Department of Health and Nutrition, Africa Region, South
Africa. ${ }^{5}$ Save the Children Zambia, Lusaka, Zambia. ${ }^{6}$ Save the Children, Westport, CT, USA.

Received: 5 August 2014 Accepted: 14 October 2014

Published online: 27 October 2014

\section{References}

1. Central Statistical Office (CSO), Ministry of Health (MOH): Tropical Diseases Research Centre, University of Zambia, and Macro International Inc: Zambia Demographic and Health Survey 2007. Calverton, Maryland, USA: CSO and Macro International Inc; 2009.

2. Ministry of Health, Zambia: National Community Health Worker Strategy in Zambia. Lusaka, Zambia: MOH; 2010.

3. Ministry of Health, Zambia: Community Health Worker's Handbook: A Reference Manual for Community Health Workers. 3rd edition. Lusaka, Zambia: MOH; 2007.

4. Keber K, de Graft-Johnson JE, Bhutta ZA, Okong P, Starrs A, Lawn JE: Continuum of care for maternal, newborn, and child health: from slogan to service delivery. Lancet 2007, 370:1358-1369.

5. Tinker A, Hoope-Bender P, Azfar S, Bustreo F, Bell R: A continuum of care to save newborn lives. Lancet 2005, 365:822-825.

6. Valentine MA, Nembhard IM, Edmondson AC: Measuring Teamwork in Health Care Settings: A Review of Survey Instruments. Med Care 2013, ISSN: 0025-7079/13/000-000

7. IOM: Crossing the Quality Chasm: A New Health System for the $21^{15 t}$ Century. Washington DC: New Academy Press; 2001.

8. Doherty RB, Crowley RA, Crowley, for the Health and Public Policy Committee of the American College of Physicians: Principles supporting dynamic clinical care teams: an american college of physicians position paper. Ann Intern Med 2013, 159:620-626.

9. Dyer J: Team research and team training: A state-of-the-art review. In Human Factors Review. Edited by Muckler FA. Santa Monica, CA: Human Factors Society, Inc; 1984:285-323.

10. Salas E, Dickinson TL, Converse SA: Toward an Understanding of Team Performance and Training. In Teams: Their Training and Performance. Edited by Swezey RW, Salas Westport E, Ablex CT. Westport, CT: Ablex Publishing; 1992:3e29.

11. Baker DP, Amodeo AM, Krokos KJ, Slonim A, Herrera H: Assessing teamwork attitudes in healthcare: development of the TeamSTEPPS teamwork attitudes questionnaire. Qualsaf Health Care 2010, 19:e49. doi:10.1136/qshc.2009.036129.

12. Business Building Information: What is the Definition of Team Work [http://businessknowledgesource.com/blog/ what_is_the_definition_of_team_work_021673.html]

13. Flin R, Winter J, Sarac C, Raduma M: Human Factors in Patient Safety: Review of Topics and Tools. In Report for Methods and Measures Working Group of WHO Patient Safety. Geneva, Switzerland: WHO/IER/PSP; 2009.

14. TEAM Measure, Sacred Heart Medical Center, PeaceHealth [http://www peacehealth.org/Oregon/SeniorHealth/TeamMeasure]

15. Gibson TL, Moore J, Lueder EJ: Teamwork in Cooperative Extension Programs. Madison, Wisconsin: Division of Program and Staff Development, University of Wisconsin-Extension; 1980.

16. Salas E, Rosen MA, Burke CS, Goodwin GF: The Wisdom of Collectives in Organizations: An Update of the Teamwork Competencies. Team Effectiveness in Complex Organizations: Cross-Disciplinary Perspectives and Approaches. New York, NY, USA: The organizational frontiers series; 2009:39-79.

17. Morgan BB, Glickman AS, Woodard EA, Blaiwes AS, Salas E: Measurement of team Behaviors in a Navy Environment. NTSC Technical Report No. TR-86-014. Orlando, FL: Naval Training Systems Centre; 1986.

18. Baker D, Salas E: Analyzing team performance: In the eye of the beholder? Military Psychol 1996, 8(3):235-245.

19. Clancy CM, Tornberg DN: TeamSTEPPS: assuring optimal teamwork in clinical settings. Am J Med Qual 2007, 22(3):214-217.

20. Schyve PM: Teamwork - the changing nature of professional competence. Jt Comm J Qual Patient Saf 2005, 31(4):183-184.

21. Clancy CM: Ten years after to Err is human. Am J Med Qual 2009, 24(6):525-528.

22. Ministry of Health: 2012-2014 Lufwanyama District action Plan. Kalulushi, Zambia: Lufwanyama District Health Management Team; 2012.

23. Yeboah-Antwi K, Snetro-Plewman G, Waltensperger KZ, Hamer DH, Kambikambi C, MacLeod W, Filumba S, Sichamba B, Marsh D: Measuring teamwork and taskwork of community-based "teams" delivering life-saving health 
interventions in rural Zambia: a qualitative study. BMC Med Res Methodol 2013, 13:84. doi: 10.1186/1471-2288-13-84.

24. Dean AG, Arner TG, Sunki GG, Friedman R, Lantinga M, Sangam S, Zubieta JC, Sullivan KM, Brendel KA, Gao Z, Fontaine N, Shu M, Fuller G, Smith DC, Nitschke DA, Fagan RF: Epi Info'm, a Database and Statistics Program for Public Health Professionals. Atlanta, GA, USA: CDC; 2011

25. Vertino KA: Evaluation of a TeamSTEPPS@ Initiative on Staff Attitudes Toward Teamwork. J Nurs Adm 2014, 44(2):97-102. doi: 10.1097/ NNA.0000000000000032.

26. Bannister SL, Wickenheiser HM, Keegan DA: Key elements of highly effective teams. Pediatrics 2014, 133:184. doi: 10.1542/peds. 2013-3735.

27. Lingard L, Espin S, Whyte S, Regehr G, Baker GR, Reznick R, Bohnen J, Orsen B, Doran D, Grober E: Communication failures in the operating room: an observational classification of recurrent types and effects. Qual Saf Health Care 2004, 13:330-334.

28. Pronovost PJ, Berenholtz S, Dorman T, Lipsett PA, Simmonds T, Haraden C: Improving communication in the ICU using daily goals. J Crit Care 2003, 18(2):71-75

29. Sutcliffe KM, Lewton E, Rosenthal MM: Communication failures: an insidious contributor to medical mishaps. Acad Med 2004, 79:186-194.

30. Alvarez G, Coiera E: Interdisciplinary communication: an uncharted source of medical error? J Crit Care 2006, 21:236-242.

31. Reader TW, Flin R, Cuthbertson BH: Communication skills and error in the intensive care unit. Curr Op Critl Care 2007, 13:732-736.

32. Roberts NK, Williams RG, Schwind CJ, Sutyak JA, McDowell C, Griffen D, Wall J, Sanfey H, Chestnut A, Meier AH, Wohltmann C, Clark TR, Wetter N: The impact of brief team communication, leadership and team behavior training on ad hoc team performance in trauma care settings. Am J Surg 2014, 207(2):170-178. doi: 10.1016/j.amjsurg.2013.06.016.

33. Salas E, Cooke NJ, Rosen MA: On teams, teamwork, and team performance: discoveries and developments. J Hum Factors Ergon Soc 2008, 50:540-547.

34. Weller J, Boyd M, Cumin D: Teams, tribes and patient safety: overcoming barriers to effective teamwork in healthcare. Postgrad Med J 2014, 90(1061):149-154. doi: 10.1136/postgradmedj-2012-131168.

35. Lehmann U, Sanders D: Community Health Workers: What Do We Know About Them? The State of the Evidence on Programmes, Activities, Costs and Impact on Health Outcomes of Using Community Health Workers. Geneva, Switzerland: WHO; 2007.

36. Ofosu-Amaah V: National experience in the use of community health workers. A review of current issues and problems. WHO Offset Publ 1983, 71:1-49.

37. WHO: Task Shifting: Rational Redistribution of Tasks among Health Workforce Teams: Global Recommendations and Guidelines. Geneva: WHO PRESS; 2008.

38. Karabi B, Peter W, Karen LB, Marie T: Community Health Worker Incentives and Disincentives: How They Affect Motivation, Retention, and Sustainability. Arlington, Virginia: Published by the Basic Support for Institutionalizing Child Survival Project (BASICS II) for the United States Agency for International Development; 2001

39. Chandler Cl, Chonya S, Mtei F, Reyburn H, Whitty CJ: Motivation, money and respect: a mixed-method study of Tanzanian non-physician clinicians. Soc Sci Med 2009, 68:2078-2088.

40. Franco LM, Bennett $S$, Kanfer R: Health sector reform and public sector health worker motivation: a conceptual framework. Soc Sci Med 2002, 54:1255-1266

41. Franco LM, Bennett S, Kanfer R, Stubblebine P: Determinants and consequences of health worker motivation in hospitals in Jordan and Georgia. Soc Sci Med 2004, 58:343-355.

doi:10.1186/s12913-014-0516-2

Cite this article as: Yeboah-Antwi et al: Can a community health worker and a trained traditional birth attendant work as a team to deliver child health interventions in rural Zambia?. BMC Health Services Research 2014 14:516.

\section{Submit your next manuscript to BioMed Central and take full advantage of:}

- Convenient online submission

- Thorough peer review

- No space constraints or color figure charges

- Immediate publication on acceptance

- Inclusion in PubMed, CAS, Scopus and Google Scholar

- Research which is freely available for redistribution

Submit your manuscript at www.biomedcentral.com/submit 